\title{
Licence to build, licence to charge? Market power, pricing and the financing of airport infrastructure development in Australia
}

\author{
A/Prof. Gui Lohmann \\ Griffith University \\ g.lohmann@griffith.edu.au \\ Dr Jakob Trischler \\ Karlstad University \\ CTF Service Research Center \\ 65188 Karlstad \\ Universitetsgatan 2 \\ Sweden \\ jakob.trischler@gmx.net
}

\begin{abstract}
In 2017, airport privatisation in Australia reached a 20-year milestone, with its regulatory framework been shifted to a light-handed regulation in 2002. The light-handed regulation (LHR), as in place at Australia's top four airports, has been suggested as the 'frontier of international policy', leading to increasing interest among transport policymakers and researchers. This article offers an in-depth examination of the LHR with focus on a) the market-power of the regulated airports, b) the commercial price negotiations between airports and airlines, and c) the airports' behaviour towards infrastructure investment. The article reports on data from 21 semi-structured interviews conducted with key stakeholder groups affected by, or with expertise in, the LHR. Findings suggest that despite airports possessing significant market power, particularly in the domestic market, the light-handed approach seems to balance the forces in a market where an airline duopoly prevails (Qantas and Virgin Australia groups). In addition, both airports and airlines perceive that commercial price negotiations are improving and refrain from a return to a stronger regulation environment. For airlines, value-for-money is the primary concern in new infrastructure investments. Interviewees also outlined specific recommendations for improving the LHR framework, including a more accessible arbitrator and improved methodologies to monitor prices and quality of service. The findings point towards the significance of vertical relationships, long-term arrangements, and transparency as key aspects of the LHR and the development of airport infrastructure.
\end{abstract}

Keywords: light-handed regulation, airport financing, infrastructure development, market power 


\section{Highlights}

- Interviewees stated that commercial price negotiations are improving

- Airlines and airports refrain from a return to a stronger regulation environment

- For airlines, value-for-money is the main concern in new infrastructure investments

- Experts suggest that a more accessible arbitrator are required

- Vertical relationships, long-term arrangements, and transparency are key to LHR 


\section{Introduction}

Australia is heavily reliant on air transport due to the long distances between its population centres, and the absence of ground transport options, especially between the major population centres and the continent's remoter regions. This reliance on air transport is corroborated by statistics from the Bureau of Infrastructure, Transport and Regional Economics (BITRE, 2010) which has forecasted a yearly increase of 4.2 per cent in passenger movements until the year 2035. By 2029-30, air passenger movements will have more than doubled (235 million movements) from their 2008-09 level. These forecasts further suggest that significant investments in infrastructure and facilities at major Australian airports will be required during the decade commencing in 2020 and beyond. Australia's airports are already recognising the need to increase investments: Brisbane Airport is currently developing a new parallel runway (AUD 1.35 billion), Sydney Airport is upgrading its international Terminal 1 (AUD 500 million), Perth Airport opened a dedicated terminal for Virgin Australia in November 2015 in addition to currently planning a new runway, and Melbourne Airport has recently opened a dedicated terminal (Terminal 4) for low-cost carriers.

There are over 2,000 airports and airfields in Australia, but only around ten percent operate to provide regular passenger services for financial reward (i.e., regular public transport services) (Productivity Commission, 2011). In 1997, the Australian Government began a privatisation process of 22 airports, concluding with the sale of Sydney Airport in 2002 (Abbott and Cohen, 2014). Accompanying the privatisation process was the recognition by the Government that some airports possessed significant market power. Therefore, privatisation was initially accompanied by a regulatory framework comprised of (a) price monitoring; (b) price caps and 'show cause' procedures for new investments; and (c) quality-of-service monitoring (Gillen, 2011; Adler, et al. 2015). With the sale of Sydney Airport, the Government introduced regulatory changes towards a light-handed price and quality of service monitoring regime (Littlechild, 2012). A light-handed regime (LHR) is a regulatory scheme that “... places no immediate constraints on aeronautical charges but monitors prices intending to 'taking action' if prices are judged to be too high" (Gillen, 2011, p.9). The regulator does not determine aeronautical charges up-front; instead, airports and airlines negotiate and agree on contracts to govern their commercial relationships (Arblaster and Hooper, 2015). The aim of this regulatory change was to minimise compliance costs for airport operators and the Government and encourage airports to undertake required aeronautical infrastructure investments that ensure economically efficiency (Productivity Commission, 2002).

While the LHR has been widely examined and discussed (e.g., Forsyth, 2008; Littlechild, 2012; Arblaster, 2014), few studies and industry reports have examined the regulatory framework from a stakeholder perspective. It, therefore, remains unclear how the key stakeholders operating under this regulatory regime perceive the light-handed approach. Opinions on the LHR diverge. For example, 
while Littlechild (2012) describes the LHR as the 'frontier of international policy' as it fosters efficiency and reduces administrative costs, other studies point to the possibility that Australia's airports might abuse their market power owing to lacking substitution between airports and other transport modes (Oum, et al. 2004; Fu et al. 2006; Forsyth, 2008). This paper contributes to this ongoing discussion by providing an in-depth investigation of how key stakeholders perceive the LHR applied to the four largest airports in Australia. Accordingly, this paper seeks to answer the following research question:

How do key stakeholders perceive the current LHR framework, particularly in terms of a) the market-power of the regulated airports, b) the commercial price negotiations between airports and airlines, and c) the airports' behaviour towards infrastructure investment?

The present article addresses this question from the perspective of key stakeholders involved, thus gives voice to those who operate under the current regulatory regime. The involved key stakeholders included Australia's major airports and airlines, government regulatory bodies, national aviation associations, and leading Australian academics who had extensive experience in the underlying topic. Thereby, the focus on the Australian case sheds light on the specific challenges of expanding and improving airport infrastructure, particularly with respect to the vertical relationships and commercial price negotiations between airports and airlines under the LHR. By bringing together the view of multiple stakeholders, the article contributes to a more nuanced understanding of the specific positions taken by key players towards the LHR and, as such, may assist policy advisors to improve its current design.

In the following section, the literature related to the LHR as currently in place in Australia' top four airports is reviewed. This section is followed by a description of the study methodology. Then, the findings from semi-structured interviews with key 21 stakeholders are presented, followed by a discussion of the theoretical and managerial implications of the key findings. The article concludes with a description of the limitations of this research and directions for future research.

\section{Literature review}

\subsection{The light-handed regulation and market power of Australia's airports}

A key aim of privatising government-owned enterprises is to improve productive efficiency (lowering costs) and allocative efficiency (producing goods and services that are attractive to the market), imposed through the competition against private firms (Domberger and Piggott, 1986). Governmentowned enterprises that typically fall into this category include telecommunications, health insurance, transport, energy and aviation. Within these sectors, firms often absorb natural monopoly characteristics due to the absence of competition or high entry barriers for new players (Abbott and Cohen, 2014). Consequently, the lack of competitive pressures in these markets usually leads to some form of regulation (Spence, 1975). However, a significant drawback of conventional regulation 
frameworks for government-owned enterprises is that they impose only a few incentives for the regulated firm to pursue productive efficiency (Laffont and Tirole, 1986). Economists, therefore, tend to argue for deregulation or the introduction of regulation incentive approaches, that is, contracts that delegate individual pricing decisions to the firm and allow the firm to reap profit increases from cost reductions (Vogelsang, 2002). In Australia, the deregulation of airports following their privatisation has been recognised as the 'frontier of international policy' (Littlechild, 2012) because it is among the first regulatory approaches that impose no direct regulatory control over prices, revenues or profits (see Abbott and Cohen, 2014, Arblaster, 2014, Forsyth, 2008, Littlechild, 2012 for a detailed overview of the evolution of airport regulations in Australia).

Currently, the Australian Government exercises an LHR which removes direct regulatory control over prices, revenues or profits, but which includes price and quality-of-service monitoring at top four airports, i.e. Sydney, Melbourne, Brisbane and Perth, by the ACCC until June 2020 (ACCC, 2014). It can be argued, however, that the approach to price and quality monitoring might be insufficient as it can allow an airport with significant market power to invest in infrastructure that might not foster the efficiency of its operation or increase the quality of service levels. In addition, the current approach might not sufficiently protect for sunk investments made by airlines, which consequently can lead to a hold-up owing to the risk that a monopolist airport could raise its prices to extract some of the value from this investment (Biggar, 2009; 2012). For example, Virgin Blue Airlines (2011, p.31) argued in an inquiry to the PC that "price monitoring alone will never be sufficient to constrain airports' market power and ensure that they provide services in an efficient manner and at appropriate prices."

Specifically, the airline suggested that (a) more transparency of cost information, (b) greater certainty in the approach taken in the pricing of aeronautical services, and (c) a credible threat of appropriate and effective sanctions are required. Although the Productivity Commission (2011) recommended a 'show cause' mechanism for new investments to strengthen the threat of a stronger regulatory measure, this recommendation has not been adopted by the Australian Government. The reason for this was partly based on the consideration that such a mechanism would increase the costs of administration and hold up necessary airport investments (Arblaster, 2014; 2016).

\subsection{Airport pricing, cost and infrastructure investment}

Important questions that arise in light of the LHR is a) how large infrastructure projects might be effectively funded by privatised airports, and b) how sunk investments made by customers (e.g., airlines) could be promoted and protected. Airport infrastructure investments require long lead-times with respect to planning, financing and construction to meet the future needs of airlines and passengers (Gillen, 2011). Privatised airports must finance their own operating and infrastructure development costs as well as diversify their revenue sources by relying not only on the revenue derived from aeronautical charges such as landing charges and ground handling services, but also 
from non-aeronautical sources such as real estate, retailing, and car park facilities (Rowley, 1997; Schulte, 2009). In fact, airports are increasingly pushed to increase revenue and reduce costs which might, incentivise short-term thinking in terms of profit generation (Aulich and Hughes, 2013; O'Donnell et al., 2011), or in contrast lead to the exploration of forming various long-term vertical relationships with downstream airlines to utilize synergy effects (Fu et al., 2011).

In Australia, the airports were sold subject to 50-year long-term lease agreements with the Australian Government, extended automatically for a further 49-year period (Productivity Commission, 2011). These lease agreements reflect the attitude of Australian investors who tend to take a strategic focus and long-term perspective on their investments. This enables airports to form strategic vertical arrangements or contracts with airlines, particularly with those that have a large market share (Fu et al., 2011). The result can be important benefits for both parties. For example, vertical relationships such as use-and-lease agreements, long-term use contracts, or revenue sharing among others can lead to service commitment and increased investments by an airline, thus reduce the airport's uncertainty surrounding future traffic and revenue. In turn, airlines can optimise their operations at the airport, strengthen its bargaining power, and generate revenue from an airport's concession services (Oum and $\mathrm{Fu}, 2008$; $\mathrm{Fu}$ et al., 2011; Yang et al., 2015). Such arrangements can also be a competitive response to other airport-airline alliances (such as e.g., between airports in London), thereby strengthen the market power of both parties as well as bring various benefits to local industries and consumers (Barbot, 2009). On the flip-side, such relationships can be anti-competitive because they strengthen an airline's dominance at an airport, thus enables the respective airline to gain a competitive advantage over other players and to charge price premiums (Barbot, 2011). However, these effects are not straightforward as they are influenced by country-specific differences, the regulatory environment, and the bargaining power of the parties involved (Yang et al., 2015).

Taking a long-term perspective is also important for airports when considering that investments such as new terminals or runways represent 'lumpy investments' (Forsyth, 2008). In other words, airports cannot incrementally increase their capacity as demand grows but instead investments often significantly increase an airport's capacity. This means that the rates of return are lower at the beginning of the asset's lifecycle due to excess capacity but rise as utilisation increases (Gillen, 2011). Therefore, in some cases, airports may consider raising their prices before the commencement of the necessary infrastructure project. This form of pre-investment in infrastructure has, for example, been (unsuccessfully) considered in the construction of capacity-building infrastructure at Brisbane Airport. Such behaviour, however, implies that an airport possesses significant market power over airlines because the airport is in the unique position of being able to increase costs, before providing the actual infrastructure (Fu et al., 2006; Forsyth, 2008).

In addition, Biggar $(2009 ; 2012)$ points out that another aspect of building large airport infrastructures 
is to promote and protect relationship-specific sunk investments made by airlines. These investments can take various forms, such as a) the construction or customisation of facilities related to the terminal, maintenance, or catering, b) the purchase or customisation of aircraft suitable for a specific airport, c) cost and time of acquiring slots, and d) the marketing of services to or from a particular airport. As stated by Biggar (2012, p. 368-9), the "construction of customised facilities (such as terminals or maintenance bases), $[\ldots]$ are subject to the conventional hold-up problem: once sunk, the airport can expropriate the value of the investment by raising its charges." Therefore, it is the role of the regulator to foster and protect sunk investments made by airlines in their hub or base airports. The absence of any protection for these sunk investments would imply that airlines will be reluctant to make the necessary investments or will invest in imperfect alternatives (e.g., using multiple underutilised airports), which can result in a loss of overall economic value (Bigger, 2012).

\subsection{Operational efficiency and related investments}

One of the primary objectives of infrastructure investments is to maintain the efficiency of airport operations. Efficiency means that the services and facilities are provided and utilised without either undue congestion or excessive spare capacity (Gillen, 2011). Thus, it is incumbent on an airport to (a) expand or retire capacity in a timely but not precipitating manner; and (b) ensure that its services and facilities are priced appropriately at any particular point in time. These outcomes, however, are not easily achievable because airports face a relatively fixed capacity (e.g., runway capacity) but fluctuating demand (i.e., peak and off-peak times). According to Forsyth and Niemeir (2008), the efficient use of airport capacity requires a suitable price structure aligned to its demand pattern, and a working slot allocation market (e.g., auction or trading). While the price mechanism could be used to shift demand from peaks to off-peak times, hence improving operational efficiency, the airports might not necessarily have the incentive to do so based on the specific regulatory structure (Forsyth and Niemeir, 2008). For example, airports operating under cost-plus regulation have no incentive for peak pricing as charges are cost related and profits cannot be raised by differentiating charges. In contrast, price-cap regulation might set incentives for peak pricing as it allows the airport to increase revenue and profits. Forsyth and Niemeir (2008) additionally point out that a number of other factors can influence an airport's decision to adopt efficient pricing, such as the specific form of price cap, ownership of airports, the strategic behaviour of airports, long-term problems related to capacity expansion, or legal and political constraints. In fact, the PC has not provided a definitive conclusion as to whether the light-handed approach has led to higher efficiency. As a consequence, it remains unclear whether price increases imposed by airports will increase operational efficiency or follow other objectives that are not directly related to improving operational efficiency (Arblaster, 2014).

On the contrary, airports argue that airline agreement to major investments is required to provide certainty to shareholders and financiers that they will earn an adequate return on their investment 
(Schuster, 2009). Therefore, it can be argued that fostering close collaboration between airlines and airports would prevent potential overpricing or unnecessary investments, investment delays, or decreasing service levels (Productivity Commission, 2011). This argument aligns with the benefits of vertical arrangements between airports and airlines (Fu et al. 2011; Barbot, 2011). However, studies also suggest that airlines can use their market power to absorb congestion costs by setting higher ticket prices and thereby controlling demand (Zhang and Zhang, 2006). Higher ticket prices can curtail demand and, consequently, deprive the airport of a primary source of funds for its capacity to invest in infrastructure (Zhang and Zhang, 2006). This problem is further exacerbated in respect of downstream transportation markets where the demand is elastic (e.g., cargo and passenger transport services offered by airlines to end-customers). Cost increases passed through to end customers might lead to lower demand in the upstream market, e.g., infrastructure services offered by airports such as rental spaces, parking, shopping facilities, etc. (Polk and Bilotkach, 2013). In other words, small changes in traffic can have large impacts on revenue as airport service provision typically involves high-fixed and low-incremental costs, therefore making a price increase unattractive (Golaszewski, 2003). Passing on costs to airlines, and from airlines to passengers, should, therefore, be approached by taking into account supply and demand elasticity.

From the examination of the literature and relevant industry reports, it becomes apparent that there are two diametrically opposite views in the debate surrounding the LHR approach. Recent concerns about the price increase or decrease in the quality of service do not indicate a failure of the LHR, as they "... are typical of the issues that arise over time in regulating any utility (Littlechild, 2012, p.61)." However, for example, Biggar (2012) and Arblaster (2014) question whether the key objectives of the light-handed approach, namely to increase operational efficiency as well as facilitate commercially negotiated outcomes between airlines and airports, have actually been met. As noted by the PC, despite negotiations have improved during the price cap period, “... relationships between some airports and their customers have been strained" (Productivity Commission, 2006, p.43) and there is "considerable scope to improve commercial negotiation especially with respect to contract formation" (Productivity Commission, 2011, p.177). No conclusions on operational efficiency appear to have been made.

\section{Methodology}

\subsection{Research design}

This research relied on qualitative data obtained from semi-structured interviews focusing on two main themes of this research: (a) market power and (b) airport pricing and financing. A statement about each theme was prepared and read to the interviewees before asking specific questions about each topic. 


\subsection{Research sample}

Seven chief financial officers (CFOs) of the major Australian capital cities and regional airports participated in this research, including one from an airport in New Zealand who had experience with the Australian regulatory framework. A representative of an airport lobbying association was also approached, and his views were included as part of the airport stakeholders (totalling eight representatives from airports, see Table 1). Furthermore, all leading domestic airlines operating in Australia, including their low cost and regional subsidiaries and a major international airline $(n=5)$ participated in the study. Two representatives from airlines associations were also invited to participate, totalling seven interviewees representing the airlines. The remaining interviewees took place with two representatives of a key regulatory body, three leading Australian academics with experience in the underlying topic, and one consultant with previous experience in price negotiation between airlines and airports $(n=6)$. Hence, a fairly balanced participation among three distinctive stakeholder groups was obtained among the 21 interviewees. Most interviews were conducted face-toface in six different cities in Australia and one overseas location between the period March and August 2015. Usually, the interviews lasted between 45 and 60 minutes. Other relevant stakeholders, including the Department of Infrastructure and Regional Development, were approached but no representative was available to be interviewed.

\section{Please insert Table 1 about here.}

A total of 17 interviewees agreed to have the interviews recorded, for the remaining notes were taken. The recorded interviews were then professionally transcribed and sent back to each interviewee to make any necessary changes. The first draft of this paper was then sent to each interviewee for their consent before submitting this article for publication.

\subsection{Analytical perspective}

The set of transcribed interviews were coded using the NVivo software. The following nodes - in NVivo, a collection of references to a specific theme - were used while analysing the transcriptions of 17 interviews: 'Market power' (15 sources; 39 references); 'Regulator: PC and ACCC' (14 sources; 42 references); 'Airlines' (14 sources; 49 references); 'Infrastructure development' (11 sources; 48 references); and 'Airport pricing and financing' (16 sources; 68 references). Of particular importance to this paper were the nodes 'Market power' and 'Airport pricing and financing' which were analysed separately, gathering responses in three main groups; i.e. airlines, airports and others. Notes from the four remaining interviewees were used to complement and support some of the results obtained.

\section{Data Analysis}


In this section, we analyse the main topics related to this paper, that is, 1) an overall perception of the regulatory framework including the market power of the regulated airports, 2) the commercial price negotiations between airports and airlines, and 3) the influence of the current regulation on airport pricing and infrastructure development. We were also interested in the aggregated views of the various stakeholders interviewed for this project and whether there are notable similarities or differences in within and/or between stakeholder groups. For this purpose, the interviewees were divided into three groups; i.e. airports, airlines, and 'other representatives' involving regulatory bodies and academics. To provide a 'base case', the section begins with an analysis of the interviewees' overall impression of the current LHR, particularly examining the market power existing in the relationship between airports and airlines (Section 4.1). The subsequent section (Section 4.2) then goes more into more depth and focuses on how the current LHR regime affects airport pricing and infrastructure development.

\subsection{Perception of the LHR and market power}

\section{Overall perception of the current regulatory framework}

Of the nine interviewees who provided their views on the statement about their perception of the LHR, five were clearly in favour. In supporting their viewpoints, interviewees made statements such as "we have always been supportive of a light-handed approach," (Executive, airline) "we favour the light-handed monitoring regime," (CFO, airport) "I think the current regime has been enormously successful in encouraging investment, particularly compared to the previously regulated model which existed prior to 2002," (CFO, airport) "I think the current regime is working. I don't think the current regime gets in the way of commercial agreements," (CFO, airport) and "I would tend to agree with that statement...The regime itself, the way it's developed, structured and works, is just looking at the cost rather than any real need for investment." (Executive, airline). One interviewee compared the current regime in regards to the previous model by stating:

"I think the current light-handed regime is very effective. Part of the regime included in the PC inquiry in 2007 or 2008 was a recommendation by the Productivity Commission that airports be monitored against their line in the sand asset values, and that wasn't based on any economic theory. It was based on a position roughly at the midpoint between what airports thought the values of their assets should be for pricing purposes and what airlines thought the value assets should be for pricing purposes. The idea of that line in the sand position was to take one of the difficult parts of a pricing negotiation out of the negotiation. That's my view on what the objective of that was, to allow the negotiation to focus more on the true commercial matters at hand rather than spending a lot of time arguing about asset values. So I think the current - the light-handed regime has been very effective in seeing investment in airport infrastructure around the country, and I think that [...] the privatisation model, is well-regarded internationally as a good model". (CFO of a state capital city airport) 
Three interviewees somehow agreed that the LHR is effective, highlighting that the monitoring of the quality of the airports was a positive element of the regulatory framework.

As an overall hypothesis, one would expect that airports are in favour of the LHR as it gives more flexibility for negotiation of prices and investments. Surprisingly, one interviewee, a CFO of a capital city airport, provided a negative view of the regulatory framework. He stated that

"the current regulatory framework is out of date, is highly inconsistent and doesn't go to the pertinent issues which are viewing the investments and the assets and the commitments going forward in current terms. It's an unhealthy mix of cost, line in the sand, arbitrary valuations and future valuations."

The 'line in the sand' approach refers to the evaluation of airport assets on a specific date (i.e., 30 June 2005) for price monitoring purposes and excludes revaluations made after that date. It is a response of the Australian Government, after stakeholders expressed concerns about airports revaluing their assets upwards, and using that as a justification for increasing charges (Schuster, 2009; Arblaster, 2014).

The criticism raised by the CFO refers to the current building block approach used by the ACCC where depreciation is considered in the investment with the price decreasing over time, as airports cannot raise investments to pay for assets unless there is an agreement with the airlines. This means that the current framework requires airports to pay for the depreciation of their investments in the years after the infrastructure has been built. A clear example of this point of view is the challenges that Brisbane airport had in the attempt to commit airlines to pre-finance the construction of its second runway. Another issue raised by the same interviewee was the difference in dealing with the airlinespecific terminals and multi-user terminals where the airport has to cater for the needs of full-service carriers and low-cost carriers simultaneously, creating immense challenges in the pursuit to obtain consensus among all airlines. When managing entire terminals for an airline, airports would have a more straightforward approach in delivering airport services catering to the needs of only one airline.

From the airlines' point of view, while their representatives were not in favour of more regulation, an overall consensus was that the current regulatory regime does not provide an ability for the regulator to act and that the "unforceful undertakings are too light." No relevant information was obtained from the group of interviews classified as 'others' (see Table 1).

\section{Market power and commercial negotiations}

All interviewees representing the airlines agreed that most airports in Australia have significant market power, particularly when compared with other regions in the world where secondary airports compete with major airports. Airports like Sydney and Melbourne were referred to as "monopolies", while airlines, at least in the current environment, operate in a duopoly environment dominated by 
Qantas (including the subsidiary Jetstar) and Virgin Australia (including the subsidiary Tiger Airways).

Relevant to the current environment, airlines pointed to the lacking availability of common use infrastructure (e.g. access to gates, check-in counters, back rooms and overall support services). One interviewee suggested that a more productive environment could be achieved if the existing infrastructure were available to all carriers, with its use dependent on schedules and which airline is flying at a given time. In the current environment, airlines have to negotiate individual commercial deals with the airport. This can be problematic for new carriers trying to enter the market or for smaller airlines operating at the airport. In particular, low-cost carriers seeking to gain access to necessary infrastructure might not be able to do so but instead are forced to use (and pay for) infrastructure they do not want (e.g. aerobridges). An executive of a low-cost carrier mentioned Brisbane Airport as a good example of how a common-use terminal structure could be designed: "having invested in new technologies such as self-serve kiosks and automated bag drops encourages much more passenger throughput and a [better] passenger experience."

Interviewees representing airports acknowledged that airports possess market power (albeit some interviewees denied this by stating that airlines have the ability to move their assets, while airports do not), but emphasised that this power applies to the domestic and not the international market. The rationale for this argument was that while domestically, most major airports are the only option for air transport arrival, international airlines flying to/from Australia have many alternatives to choose from. The interviewees noted that international airports based in Australia compete with airports and regions around the world to attract and generate traffic to their catchment areas. In some cases, the desire to compete internationally for accommodating the most advanced and modern aircraft models such as the A380, A350 and the B787. On the flipside, it might be argued that a home base carrier like Qantas must maintain a level of international presence at the Australia's international gateway ports. As a counter example, no international flights are offered by Qantas and Virgin Australia at Adelaide Airport, which is predominantly operated by foreign carriers.

In addition, interviewees representing airports suggested that airlines might also possess market power. For example, an interviewee from a major airport pointed out that while individually international airlines might not have a lot of market power to negotiate, airlines might "talk to each other both unofficially - which they are not supposed to be doing - and [...] via BARA [Board of Airline Representatives of Australia] which they are allowed to." These conversations might enable individual airlines with a weaker market power to coordinate their actions as a group and put them in a stronger negotiation position. Airline representatives, however, strongly opposed these arguments. In fact, an interviewee representing an airline argued that airports could use the current airline duopoly environment to their advantage: 
"You will often find the airports will use that to their advantage. So they will say to us, we're not agreeing to that because [name of airline] has agreed to it over here. So then we're not only up against a monopoly; we're up against what they've agreed with our competitor - supposedly. We can't prove it." (Executive of a leading airline group in Australia)

Airports might come to the negotiation table stating that an airline competitor has agreed to the project. An interview from a major airline reported that while varying from one airport to the other, "it is becoming a trend where the airports are offering less transparency - most likely because airlines are becoming slightly more sophisticated in negotiations."

Regarding the length of the negotiated contracts, most of the contracts are set for five years, albeit airlines are also committing to longer contracts ranging from 10 to up to 40 years (e.g., with Adelaide Airport). From the airlines' point of view, the market information which accompanies the negotiations tend to be based on very low passenger number forecast, so it is not difficult for airports to benefit if passenger numbers increase. Airports also include a risk premium to protect from demand uncertainty. Yet, airports are becoming more aware of the need to disclose their information and to have airlines involved early in their capital expenditure exercises. However, from the airlines' point of view, pre-financing is not acceptable because they take a very different approach to their investments. While airlines are more sensitive to cash flow, with airline shareholders having a more immediate interest in the profitability of their businesses, most airports are financially backed by superannuation funds which have a long-term perspective on their asset investment. With airports building for peak capacity, it takes time for the demand to catch up and to make the project viable.

The insights derived from the analysis of the stakeholders' perception of the LHR, including the commercial price negotiations between airports and airlines, suggest that both airports and airlines do prefer the LHR over stronger regulatory frameworks. In addition, while airports agree that they possess market power within the domestic market, they also point out the possibilities of airlines having countervailing power. The following key points evolve from this section:

- Airports critique the 'line in the sand' and building block approach as impractical because it does not acknowledge the real value of the asset in question;

- Airports suggest that their market power applies predominantly to the domestic and not the international market;

- Airports argue that smaller airlines with weaker market power could coordinate their actions as a group and put them in a stronger negotiation position;

- Airports argue that airlines can have countervailing power by posing a threat to move their assets to another basis/hub airport;

- Airlines critique that airports apply unrealistically low passenger forecasts during pricing negotiations;

- Airlines raise concern over common use over access to suitable airport infrastructure;

A number of interviewees not belonging to either airlines or airports found it difficult to express their 
opinions about the topic, predominantly because as regulators they were not entitled to have a particular view of the matter or because they could articulate a more impartial point of view considering the advantages.

\subsection{Airport pricing and infrastructure development}

In this section, the focus turns on the influence of the LHR on airport pricing and infrastructure development, specifically to the questions as to whether the LHR supports investments and/or whether prices did increase under the LHR. Table 2 provides an overview of the responses provided by the three stakeholder groups. The different viewpoints are analysed in further depth below.

\section{Please insert Table 2 about here.}

\section{Airport infrastructure development}

The majority of respondents agreed that the LHR supports airport investments (11 in support, 3 against and 5 did not provide an answer - see Table 2). Surprisingly, while six airport representatives agreed that the LHR fosters airport investments, one airport CFO opposed these views. Specifically, he stated that airlines are only interested in investments that foster their operations and are not interested in investments that increase passenger comfort (e.g. by paying to have airbridges installed at some airports). According to the same interviewee, airlines do invest in lounges to captivate their premium passengers, but beyond this "it is all about the operational efficiency". As supported by one of the interviewees representing a major Australian airline:

"I think the message we try and send our airports pretty clearly is we are willing to invest where it makes sense. We are not willing to invest where it doesn't. There's too much airport activity that doesn't make any difference to us."

One example provided during the interviews to illustrate this standpoint was a regional airport in Queensland proposing a $\$ 60$ million redevelopment. The interviewee questioned the reason why airlines should pay higher prices considering it is unlikely that this redevelopment will contribute to an increase in air traffic. Instead, according to the same interviewee, the benefits of the redevelopment rest with the airport and the concessions existing at the terminal. This standpoint seems to suggest that airlines are more interested in traffic generation and their operations, while airports favour travel experiences which subsequently can leverage passenger expenditures on the airport.

Airport interviewees in support of the LHR suggest that evidence that the current system is working can be found in the amount of investment that has recently been made in airport infrastructure. These significant investments should be considered in the context that incremental investment in airports is not always possible, as previously discussed in this paper. In comparing the LHR with the previous regulatory environment, two airport CFOs stated: 
"If an airline wants a certain amount of capital spent - they want a new lounge, or they want a new catering facility, or they want a new something at the hangar, or they want to do something with the customer experience, they can meet with [us]. We can talk to them about their needs, and we can come up with a win-win solution to help them. If we were a regulated asset, they would have to go to the government and get the government across it. It would have to be an asset that would be necessarily incurred and all sorts of stuff. So I think having a commercial environment where airlines can pursue their commercial objectives and airports can also pursue their commercial objectives in a win-win [proposition], is better for both of us" (CFO of a capital city airport)

"I think the current regime has been enormously successful in encouraging investment, particularly compared to the previously regulated model which existed prior to 2002. [...] I think the airlines would agree with that too. That was a period where there was very little - the airports were privatised in 1997, 1998, and there was virtually no investment made in airports from then until 2002 because of the difficulty of generating a price increase to support the investment. Everything had to go through the ACCC, and it just got bogged down." (CFO of a capital city airport)

While supporting the LHR, another airport CFO also pointed towards the complexities related to not only where to invest, but also its timing and amount. According to the interviewee, not investing can have serious consequences, such as the remove of the licence to operate. He additionally suggested that the media and the community do not care when airports lose money by over-investing, but they are very fast to complain when airports are successfully profitable in terms of their decisions to invest:

"The other aspect is that if you are under-earning there is no debate. If you are over earning there is a stick. Airports need to balance all of that. If you continue to underinvestment, you will lose the 'licence to operate'. The community and passengers will complain: noise, the second airport, curfews, etc. are put in place before they don't have the full licence. That destroys value. Balancing the risk goes to value. The timing is a crucial one as well, not just the amount of investment, but where to invest." (CFO of a capital city airport)

In terms of the perspectives derived from the airline representatives, three agreed that the LHR supports investments, while two disagreed and two interviewees did not clearly have a position about this topic. By supporting the current LHR, airline representatives stated that airports are not delaying investments and that currently there has been a lot of investment in infrastructure development. One of them, however, cautioned about the ability of these investments to continue in the future, as the capacity to be added to the current round of investments will last for many years. The two airline representatives that disagreed that the LHR supports investments were from the same legacy carrier, albeit they were interviewed separately. One of them mentioned that some airports were better than others in fulfilling their investment commitments. He stated that there was no accountability in regards to when investments were redirected to other projects, particularly blaming a lack of transparency in this process: 
"I think in the past the airports would just go and build whatever and spend a lot of money on building infrastructure to facilitate what they thought was the needs, but, I think there is a level of improvement between the airlines and airport about the need for infrastructure going forward. But there's a long way to go before we get a better alignment on balancing on what the airlines believe needs to be developed for infrastructure, versus what the airports believe they need to do. So some airports are better than others in terms of managing that infrastructure investment."

In the past, negotiations with airlines over the use of infrastructure and services would start between two and three years in advance of the investment decision is made. The timeframe can vary according to the size of the project and the amount to be invested. A charging mechanism would usually be attached to the commercial negotiation. If no agreement is reached, the airport operator needs to decide whether to go ahead with the development or not. A myriad of pathways is available to airport operators to mitigate the failure to reach an agreement. At one end of the spectrum, an airport could pursue a judicial remedy against an airline for failure to reach agreement; an extreme example would be litigating against the airline (which has not happened yet). On the other end of the spectrum, an airport could decide to abandon the project altogether. Overall, one of the interviewees from a major airport considers that "the commercial negotiation is becoming easier, and it's becoming more commercial." He recounted that while in the past, negotiations used to involve two years "of wasted time," most negotiations currently are finalised within six to seven months. In a similar vein, also an airline representative suggested improvements in negotiations albeit noting that some difficulties still remain:

"I think in the past the airports would just go and build whatever and spend a lot of money on building infrastructure to facilitate what they thought was the needs, but, I think there is a level of improvement between the airlines and airport about the need for infrastructure going forward. But there's a long way to go before we get a better alignment on balancing on what the airlines believe needs to be developed for infrastructure, versus what the airports believe they need to do. [...] Some airports still have a simple philosophy of, well this is what I think needs to happen and this is how much we think it's going to cost [...] I think there's a bit of that still, but I think that has improved and it continues to improve, as the relationship between the airlines and the airports starts to mature over the years." (Executive of a leading airline group in Australia)

Apart from the airport and airline representatives, four out of six interviewees did not make a clear statement supporting or not the current LHR, with two interviewees stating they consider the LHR supports investment. No significant quotes were identified among this group of stakeholders, except the comment from one representative of a regulatory agency stating that the current regulatory framework "is not constraining investment". However, he posed the question that if delays in investments are happening, he would be interested in knowing what would be constraining the behaviour. 


\section{Airport Pricing}

In terms of the perception of airport pricing under the LHR, five interviewees stated that prices increased under the LHR, while eight respondents disagreed with this argument. Eight participants did not comment on this topic (see Table 2). The following quote illustrates one of many viewpoints on airport pricing under the LHR:

"What you see in terms of that large investment, large price increase is a reflection of the way the system works which is the newer the investment, the larger the base for returns [...]. So, the older your assets, the lower your price. The newer your assets, the higher your price because you've got more current capital deployed that needs to produce a return, be it debt and equity. [...] Clearly, the more we invest, the higher fees because that's the nature of our return but the nature of that investment is heavily negotiated with the airlines to meet their requirements" (CFO of a capital city airport)

Airport interviewees not supporting the statement that prices increase under the LHR, commonly stated that the negotiation framework provided by the current regime favours airlines to only accept projects that they are willing to pay. One interviewee, representing a low-cost airport, stated that "I see that the airports find it increasingly difficult to progress with developments because of the need [of airlines] to try to secure pricing [advantages]". Obviously, airports that have not received investments would still be cheaper than those where investments have been made.

In terms of responses from airlines representatives, one interviewee suggested that price did not increase under the LHR. This interviewee, a representative of a low-cost carrier, stated that the value for money of the new infrastructure can be a lot more appealing, particularly when properly designed to address specific issues of the airlines. He gave the example of an airport that was building a brand new low-cost terminal where the "price for that is a small increase on what we're currently paying, but the infrastructure we'll get in return will be far superior to the infrastructure that we've had in [name of the airport] previously". The underlying aspect of the comment provided by this interviewee might be related to the LHR encouraging airports to develop long-term arrangements with selected airlines to foster collaborative infrastructure developments.

Three airline representatives stated that the LHR tends to increase airport prices. One airline representative stated that his airline, in judging whether the prices were fair or not, would also consider what would be the price charged if airports were in a deemed declaration situation, where the arbitrator/regulator was ruling the price. He believed that, under the LHR, most airports charge prices above what the "ACCC would deem appropriate". Another airline interviewee expressed the concern that albeit the ACCC's yearly reports state that there has been an increase in price, the quality of service levels remain the same. The same interviewee also argued that he does not believe that the regulator would actually act to intervene, albeit clearly spotting that airport operators are overcharging their customers. 
The group comprising 'other' interviewees' opinions were split, with three perceiving no price increase related to the LHR, and three not addressing this topic. One of the respondents in support of the LHR stated that over the length of the lease, if airports are not doing a "good job", they would be caught up in the review that is conducted every five years, implying that if they do not invest the price will come down. One of the interviewed academic referred to a previous example to support his argument, stating that "if you look at 2004, what happened in 2004, is the Sydney Airport wanted to increase the price. Virgin Blue and Qantas got very upset. They filed a suit to Australian Competition Tribunal. It took some million dollars, but eventually Virgin Blue has won the case." This summarises the long and costly battle that can be involved when airlines go to the regulator to address issues related to the LHR.

The analysis of the perceived influence of the LHR on airport pricing and infrastructure development led to a number of different viewpoints between airports and airlines. The main findings from this section are as follows:

- The LHR appears to encourage airport infrastructure developments. However, this factor additionally seems to be influenced by the specific relationship between airport and airlines;

- While commercial negotiations between airports and airlines on new investments seem to become easier, transparency during the negotiations is considered as a key to finding an agreement;

- Airports argue that airlines have the power to agree on investments that do not suit their requirements;

- In terms of committing to new developments, airlines seem to primarily be focused on improving their operational efficiency, while airports also aim to improve the airport experience for the passengers;

- An airport delaying infrastructure investments is not only deemed bad business practice but can also lead to an airport losing its licence;

- Despite the perception of price increases, airlines emphasise value for money of new investments - while new infrastructure might be more expensive, it can also create long-term benefits when customised to the requirements of a specific airline;

\section{Discussion and implications}

The present research examined the LHR with focus on the following key areas: a) the market power of regulated airports, b) the commercial price negotiations between airports and airlines, and c) the airports' behaviour towards infrastructure investment. The article brought together the views of multiple stakeholders including airport and airline executives, representatives from government regulatory bodies and national aviation associations, and leading Australian academics within the field. In so doing, not only gives the article voice to airport operators and experts to express their opinions on the LHR, but it also provides important insights into the specific opportunities and challenges related to the timely development of airport infrastructure. The paper concludes with discussing the implications of the research's findings with link to previous theoretical and empirical studies conducted in this field. An overview of the key findings is provided in Table 3. 
The overall perception among the interviewed stakeholders is that the LHR is more effective than the previous airport-specific price cap regulation. Most interviewees rejected a return to stronger regulation. A notable exception is Qantas Group which holds the position that “... airports generally need to be subject to an effective access and pricing regime" (Australian Government Treasury, 2015, p. 4; emphasis in original). Qantas' statement reflects the position that Australia's airports might, at least partly, possess significant market power (Forsyth, 2008). In Australia, particularly the lacking substitutes imply that airports have market power over local traffic due to the low price elasticity of their aeronautical services (Fu et al., 2006). In addition, the argument that concession revenues from activities, such as retailing, car parking and rental, banking, and catering might deter an airport to increase aeronautical charges is not sufficiently grounded (Fu et al., 2011). On the contrary, there are some indications suggesting that the dominant airlines in Australia might possess countervailing power. Notably, Australian domestic market is dominated by two carriers, which both have long-term leases on terminals at main airports in Sydney, Melbourne, Perth, and Brisbane. These arrangements can a) give dominant airlines control over key airport facilities, and b) lead to synergy effects that increase the entry barriers for potential new carriers, thus raising anti-competitive concerns (Barbot, 2009; D'Alfonso, et al., 2012). In fact, stakeholders raised concerns about the availability of common use infrastructures and the problems related to smaller airlines wishing to enter or operate in the market. Yet the costs and benefits of such arrangements can depend on many factors beyond the regulatory framework, thus require exploration on a case-by-case basis (Fu et al., 2011). It is, therefore, important to assess an airport's market power based on an in-depth investigation of the particular economic circumstances present (Polk and Bilotkach, 2013).

A further explanation for most stakeholders preferring the LHR over other regulatory designs might be related to specific benefits outweighing its limitations. Deregulation allows all players to drive investments that are economically efficient, reduce compliance costs, and reap profit increases (Vogelsang, 2002). The LHR appears to encourage airports to provide the services that are preferred by airport customers and to ensure greater efficiency through investment in infrastructure and innovation (Littlechild, 2012). Opposing views are presented by studies showing that airports operating under the LHR have the ability and incentive to increase airside service charges substantially, which particularly harms the ability of low-cost carriers to compete. For example, Fu et al. (2015) find that unregulated aeronautical pricing by a monopoly airport is likely to impact negatively on the competition in the downstream air transport markets to and from that airport. As their study further shows, this can especially harm low-cost carriers in their outputs and profits. Lowcost carriers run on very thin margins, and in some cases, where they are forced to operate from expensive airports (e.g., hub airports), the airport charges can represent up to $20 \%$ of the total airfare 
(Tretheway and Markhvida, 2014). Nonetheless, following from the current perception, it appears that the current regulatory design, in combination with the airline duopoly and the long-term relationships between airports and airlines works, at least for the two main players involved. It remains unclear, however, how these unique constellations may affect the passenger as end-user, particularly in the use of concession services, such as retailing or parking, which have recently been under public scrutiny owing to the large price increases over the past years.

Moreover, the price negotiations between airports and airlines seem to have become 'more commercial' as agreeable outcomes are increasingly reached within a reasonable timeframe. Representatives of both airports and airlines repeatedly stressed that they have 'good relationships', perceiving each other as partners that are dependent upon each other. This finding suggests a stepwise development towards commercial conditions given that the PC observed in its recent report that there is "considerable scope to improve commercial negotiation especially with respect to contract formation" (Productivity Commission, 2011, p.177). In addition, it highlights the importance of vertical arrangements between airlines and airports in Australia. Most recent examples in terms of such long-term arrangements are the new Terminal 4 at Melbourne Airport solely designated to the low-cost carriers Tiger Airways and Jetstar Airways, and the Domestic Terminal 1 at Perth operated by Virgin Australia. On the one hand, these commitments made by airlines suggest that the current framework might promote and protect relationship-specific sunk investments made by airlines (Bigger, 2009; 2012): airlines tend to commit to making necessary sunk investments despite the risk that the airport might expropriate the value of the investment by raising its charges. On the other hand, it might exactly be this reason why airlines seek long-term agreements as they enable airlines to improve operational efficiency and at the same time guard against airport user charge increases. While vertical contracts, particularly the operation of terminals or other airport facilities by airlines, may be anti-competitive, politicians might still support these arrangements to enhance economic welfare (e.g., employment) (Barbot, 2011).

Notably, airports and airlines provided specific recommendations for improving the current LHR framework. Airlines recommended access to an arbitrator to 'level the playing field' during negotiations with airports that possess significant market power. This recommendation highlights the importance of an independent regulatory body or mediator between airports and airlines which can impose a 'credible threat' to airports with market power (Forsyth, 2008; Arblaster, 2016). A similar recommendation has been forwarded by Littlechild (2012, p.57) suggesting that "independent dispute resolution would strengthen the airlines' hand in negotiating terms and conditions with airports". This topic has also been a major theme of the 2013-14 Airport Monitoring Report (ACCC, 2014) noting that, although the current declaration process provides a credible option for airlines and other airport users, they face considerable uncertainty and protracted time periods complying with the declaration 
process. Consequently, the ACCC (2014, p.20) suggested that

"an additional consideration for airport and airline negotiation may be deemed declaration. Deemed declaration could, to a degree, limit the incentive for the airports to exercise market power and facilitate the development of more effective commercial relationships. This matter exists because airlines could credibly threaten the airports with ACCC arbitration where negotiations are unsuccessful."

Policy makers need to find the fine line to balance the negotiation power between airports and airlines through an independent dispute resolution process because an arbitrator might not only lead to increased administration costs but might also inadvertently delay airport investments.

Airports, in turn, suggest that the so-called 'building block approach', as used by the ACCC, can lead to lengthy negotiations and delay investments because it requires airports to reach an agreement with the airlines. This method proves especially difficult in infrastructure that is operated by multiple users with different interests such as full-service and low-cost carriers. In contrast, airlines suggest that particularly for a monopoly provider, it is important to reach an agreement with their customers about the charges for the respective facilities and services, prior to those facilities and services being committed to. Airlines further criticised that airports could manipulate the inputs into the building block model to gain the maximum revenue, resulting in increased operational prices. For example, Virgin Blue Airlines (2011, p.26) argued that airports continually applied lower passenger forecasts during pricing negotiations than would be reasonably predicted in the light of historical passenger numbers and forecast demand. This strategy allowed them to divide their return over a smaller number of passengers, consequently leading to higher per passenger charges. Given the limitations of the building block model, the Board of Airline Representatives of Australia (2012) recommended that airports be required to disclose details about future revenues, costs and the cost of capital used as this would provide a clearer basis for the current regulatory regime and future price negotiations with airlines. While negotiations between airports and airlines seem to have improved over the last ten years, it was also highlighted by both airlines and airports that negotiation partners became less transparent particularly in the allocations of the agreed price increases and the provision of forecast models (see, e.g., Australian Government Treasury, 2015). Resolving these issues around information requirements and reporting arrangements will be an important step towards ensuring commercial negotiations between airport operators and their customers (Arblaster, 2014). In fact, transparency and public scrutiny, as suggested by $\mathrm{Fu}$ et al. (2011), might be effective to deter anti-competitive behaviour resulting from vertical arrangements, and as such present a cost-effective alternative to regulatory measures with uncertain consequences.

\section{Conclusion and avenues for future research}

The research reported in this paper is necessarily broad in its focus and investigation. The findings 
suggest that the LHR encourages airports to undertake required operational infrastructure investments. The findings further suggest that the light-handed approach might facilitate commercially negotiated outcomes between airlines and airports. However, due to its qualitative approach, no conclusions can be made on the actual operational efficiency concerning operational infrastructure developments. Future research is required to investigate this relationship as the facilitation of operational efficiency forms key objectives of the light-handed approach.

Further, the current study provides an overarching perspective on the perception of the LHR in place at Australia's major airports. It should be noted, however, that each airport represents a very particular case with multiple factors to be accounted for, including its relationship with the principal stakeholders and its behaviour towards infrastructure investments. This means that the assessment of market power and the LHR requires an analysis of the relevant economic circumstances of the specific airport under investigation (Polk and Bilotkach, 2013; Yang et al., 2015). An important avenue for future research is to investigate Australia's airports on a case-by-case basis with a particular focus on the ownership structure, services provided, investment behaviour and economic circumstances in which they operate.

Finally, while the paper sheds light on the topics of market power and financing infrastructure development, other areas require further investigation. For example, a possible avenue for future research could be a detailed examination of the methodology deployed by the ACCC to monitor the airports' price and quality of service levels. Hereby, a similar approach from the one used in this study, namely obtaining the perspective of multiple stakeholders, could be useful to understand the current perception of the methodology and reporting standards used by the ACCC. The insights can help to further improve the current monitoring approach and explore possibilities of government regulatory bodies playing a mediator or arbitrator role between negotiation partners with unequal market power. Hereby, an additional avenue for future research could be to investigate alternative ways to finance infrastructure developments and the role that passengers can have in this process. While it might be difficult to incorporate passengers into commercial negotiations, it is worth considering the power that passengers have and their willingness to pay for new infrastructure development.

\section{Acknowledgements}

The authors acknowledge the financial support received to undertake this research which is part of a university-industry collaboration scheme grant in partnership with Queensland Airports Ltd (QAL). The first author is particularly grateful to Chris Mills and Dennis Chant, respectively current and former QAL's Managing Directors, and Craig Shawn (former QAL Services' Chief Operating Officer). The usual disclaimer applies. 


\section{References}

Abbott, M., and Cohen, B. (2014) A Survey of the privatisation of government-owned enterprises in Australia since the 1980s. Australian Economic Review, 47 (4), 432-454.

ACCC (2014) Airport Monitoring Report 2013-14. Canberra: Australian Competition and Consumer Commission.

Adler, N., Forsyth, P., Mueller, J., and Niemeier, H. M. (2015) An economic assessment of airport incentive regulation. Transport Policy, 41, 5-15.

Arblaster, M. (2014) The design of light-handed regulation of airports: Lessons from experience in Australia and New Zealand. Journal of Air Transport Management, 38, 27-35.

Arblaster, M. (2016) Negotiate-arbitrate regulation of airport services: Twenty years of experience in Australia. Journal of Air Transport Management, 51, 27-38.

Arblaster, M., and Hooper, P. (2015) Light handed regulation - Can it play a role in the developing world? Transport Policy, 43, 32-41.

Aulich, C. and Mark H. (2013) Privatizing Australian airports: Ownership, divestment and financial performance. Public Organization Review, 13 (2), 175-184.

Australian Government Treasury (2015) Qantas Group submission on Harper review recommendations. Available at:

http://www.treasury.gov.au/ /media/Treasury/Consultations\%20and\%20Reviews/Consultatio ns/2015/Competition\%20Policy\%20Review\%20Final\%20Report/Submissions/PDF/Qantas\% 20Group\%20Submission.ashx.

Barbot, C. (2009) Airport and airline competition: Incentives for vertical collusion. Transportation Research Part B, 43 (10), 952-965.

Barbot, C. (2011) Vertical contracts between airports and airlines: Is there a trade-off between welfare and competitiveness? Journal of Transport Economics and Policy, 45 (2), 277-302.

Biggar, D.R. (2009) Is protecting sunk investments by consumers a key rationale for natural monopoly regulation? Review of Network Economics, 8 (2), 128-52.

Biggar, D.R. (2012) Why regulate airports? A Re-examination of the rationale for airport regulation. Journal of Transport Economics and Policy, 46 (3), 367-380.

BITRE (2010) Aviation: Aircraft movements through capital city airports to 2029-30. Canberra: Bureau of Infrastructure, Transport and Regional Economics.

Board of Airline Representatives of Australia (2012) Scope of Airport Quality of Service Monitoring. Available at: http://www.bara.org.au/baras-voice/bara-newsletter/2010-archive/december2012/158-scope-of-airport-quality-of-service-monitoring-must-be-maintained.

D'Alfonso, T. and Nastasi, A. (2012) Vertical relations in the air transport industry: A facility-rivalry game. Transportation Research Part E, 48, 993-1008.

Domberger, S., and Piggott, J. (1986) Privatization policies and public enterprise: A survey. Economic Record, 62(2), 145-162.

Forsyth, P. (2008) Airport policy in Australia and New Zealand: Privatization, light-handed regulation, and performance. Aviation Infrastructure Performance: A Study in Comparative Political Economy, Madrid: Fundacion Rafael del Pino, 65-99.

Forsyth, P. and Niemeier, H.M. (2008) Price regulation and the choice of price structures at busy airports. In A. Czerny, P. Forsyth, D. Gillen and H.M. Niemeier (eds), Airport Slots International Experiences and Options for Reform. Aldershot: Ashgate, 127-148.

$\mathrm{Fu}, \mathrm{X}$., Lijesen, M. and Oum, T.H. (2006) An analysis of airport pricing and regulation in the presence of competition between full service airlines and low cost carrier. Journal of Transport Economics and Policy, 40, 425-447.

$\mathrm{Fu}, \mathrm{X}$. and Zhang, A. (2010) Effects of airport concession revenue sharing on competition and social 
welfare. Journal of Transport Economics and Policy, 44 (2), 119-138.

Gillen, D. (2011) The evolution of airport ownership and governance. Journal of Air Transport Management, 17 (1), 3-13.

Golaszewski, R. (2003) Network industries in collision: aviation infrastructure capacity, financing and the exposure to traffic declines. Journal of Air Transport Management, 9 (1), 57-65.

Laffont, J.J. and Tirole, J. (1986) Using cost observation to regulate firms. The Journal of Political Economy, 94(3), 614-641.

Littlechild, S. C. (2012) Australian airport regulation: Exploring the frontier. Journal of Air Transport Management, 21, 50-62.

O'Donnell, M., Glennie, M., O'Keefe, P., and Kwon, S. H. (2011) Privatisation and 'light-handed' regulation: Sydney airport. The Economic and Labour Relations Review, 22(1), 65-80.

Oum, T. H., Zhang, A., and Zhang, Y. (2004) Alternative forms of economic regulation and their efficiency implications for airports. Journal of Transport Economics and Policy, 28, 217-46.

Oum, T. H., and Fu, X. (2008) Impacts of airports on airlines competition: Focus on airport performance and airports-airlines vertical relations. Joint Transport Research Centre, International Transport Forum, OECD.

Phang, S. Y. (2016) A general framework for price regulation of airport. Journal of Air Transport Management, 51, 39-45.

Polk, A., and Bilotkach, V. (2013) The assessment of market power of hub airports. Transport Policy, 29, 29-37.

Productivity Commission (2002) Price Regulation of Airport Services. Canberra: Productivity Commission.

Productivity Commission (2006) Review of Price Regulation of Airport Services. Report no. 40, Canberra: Productivity Commission.

Productivity Commission (2011) Economic Regulation of Airport Services. Canberra: Productivity Commission.

Rowley, C. R. (1997) Financing airport capital development: The aviation industry's greatest challenge. Journal of Air Law and Commerce, 63, 605-31.

Schulte, S. (2009) Financing airport infrastructure: The Fraport perspective. International Transport Forum. Leipzig: International Transport Forum.

Schuster, D. (2009) Australia's approach to airport charges: The Sydney Airport experience. Journal of Air Transport Management, 15 (3), 121-126.

Spence, A.M. (1975) Monopoly, quality, and regulation. The Bell Journal of Economics, 6 (2), 417429.

Tretheway, M. W. and Markhvida, K. (2014) The aviation value chain: Economic returns and policy issues. Journal of Air Transport Management, 41, 3-16.

Virgin Blue Airlines (2011) Productivity Commission Inquiry: Economic regulation of airport services. Canberra: Productivity Commission.

Vogelsang, I. (2002) Incentive regulation and competition in public utility markets: A 20-year perspective. Journal of Regulatory Economics, 22(1), 5-27.

Yang, H. and Fu, X. (2015) A comparison of price-cap and light-handed airport regulation with demand uncertainty. Transportation Research Part B, 73, 122-132.

Yang H., Zhang A. and Fu X. (2015) Determinants of airport-airline vertical arrangements: Analytical results and empirical evidence. Journal of Transport Economics and Policy, 49(3), 438-453.

Zhang, A. and Zhang, Y. (2006) Airport capacity and congestion when carriers have market power. Journal of Urban Economics, 60(2), 229-247. 
Table 1. Details of the research sample.

\begin{tabular}{llll} 
ID & Background & Description of respondents' background & Data source \\
\hline 1 & Airline & Executive of a low-cost carrier & Transcript only \\
2 & Airline & Executive of a leading airline group in Australia & Transcript and notes \\
3 & Airline & Executive of a leading airline group in Australia & Transcript only \\
4 & Airline & Executive of a leading airline group in Australia & Transcript only \\
5 & Airline & Executive of a regional airline & Notes only \\
6 & Airline & Representative of an airline association & Transcript and notes \\
7 & Airline & Representative of an airline association & Notes only \\
8 & Airport & Representative of an airport association & Transcript and notes \\
9 & Airport & CFO of a predominantly low-cost airport & Transcript and notes \\
10 & Airport & CFO of a capital city airport & Transcript only \\
11 & Airport & CFO of a capital city airport & Transcript and notes \\
12 & Airport & CFO of a capital city airport & Transcript only \\
13 & Airport & CFO of a major airport in New Zealand & Transcript and notes \\
14 & Airport & CFO of a capital city airport & Transcript and notes \\
15 & Airport & CFO of a capital city airport & Transcript and notes \\
16 & Other & Representative of a regulatory agency & Notes only \\
17 & Other & Representative of an aviation consulting company & Transcript and notes \\
18 & Other & Representative of a regulatory agency & Notes only \\
19 & Other & Academic with expertise in the topic & Transcript and notes \\
20 & Other & Academic with expertise in the topic & Transcript only \\
21 & Other & Academic with expertise in the topic & Transcript only \\
& & &
\end{tabular}


Table 2. Summary of the interviewees' standpoints.

\begin{tabular}{lllllllllll}
\multirow{2}{*}{ Statement } & \multicolumn{4}{c}{ Airports $(n=8)$} & \multicolumn{3}{c}{ Airlines $(n=7)$} & \multicolumn{4}{c}{ Others $(n=6)$} \\
& Yes & No & N/A & Yes & No & N/A & Yes & No & N/A \\
\hline LHR supports investments & 6 & 1 & 1 & 3 & 2 & 2 & 2 & -- & 4 \\
Price increases under LHR & 2 & 4 & 2 & 3 & 1 & 3 & -- & 3 & 3 \\
\hline
\end{tabular}

N/A - no answer provided 
Table 3. Overview of the study's findings.

\section{Key issues under examination}

\section{Market-power of the regulated airports}

LHR is among the first regulatory approaches that impose no direct regulatory control over prices, revenues or profits.

Australian main airports possess significant market power owing to lacking substitutes

Market power might allow airports to decrease the quality of services or delay infrastructure investments to increase profits.

\section{Commercial price negotiations between airports and airlines}

Airports seek to form strategic vertical arrangements or contracts with airlines, particularly with those that have a large market share.

Vertical relationships can a) reduce the airport's uncertainty surrounding future traffic and revenue, and b) allow airlines to optimise their operations at the airport, strengthen its bargaining power, and generate revenue from an airport's concession services. LHR might not sufficiently protect for sunk investments made by airlines leading to a hold-up problem.

\section{Behaviour towards infrastructure investmen}

Airport infrastructure investments require long lead-times with respect to planning, financing and construction.

It is unclear whether price increases imposed by airports increase operational efficiency or follow other objectives (concession services).

Efficient use of airport capacity requires a price structure aligned to its demand pattern, and a working slot allocation market.

\section{Selected key publication}

Fu et al. (2006)

Forsyth (2008)

Littlechild (2012)

(2012)

Zhang \& Zhang (2006)

Oum \& Fu (2008)

Biggar $(2009 ; 2012)$

Arblaster $(2014 ; 2016)$

Yang et al. (2015)

\section{Key findings of the current study}

Airport market power might apply predominantly to the domestic market in which airlines seem to have countervailing power.

The LHR appears to encourage airports to provide services that are preferred by airport customers and increase efficiency through investment in new infrastructure and innovation.

It seems that the LHR works for the involved key stakeholders, but this perception seems to be additionally influenced by the current airline duopoly (Qantas and Virgin Australia groups) and the long-term relationships between airports and airlines.

Airports and airlines seem to seek to form strong relationships to leverage synergy effects and to protect their investments.

The vertical relationships between airports and airlines appear to reduce the availability of common use infrastructure and increase the entry barriers for new carriers.

The perception is that commercial negotiations between airports and airlines on new investments became easier, with transparency considered as a key aspect to finding an agreement.

Access to an arbitrator during the negotiations might be an approach to 'level the playing field' between airlines and airports that possess significant market power.

Forsyth \& Niemeir (2008) The LHR appears to encourage airport infrastructure developments, but while Barbot $(2009 ; 2011)$ airlines seem to be primarily concerned with improving operational efficiency, airports also aim to improve the airport experience for the passengers.

Recent investment strategies point towards customising infrastructure to the specific airline requirements (e.g., low-cost carriers) suggesting value for money as the key focus.

Customised infrastructure backed up by long-term agreements seem to enable airlines to improve operational efficiency and at the same time guard against price increases. 